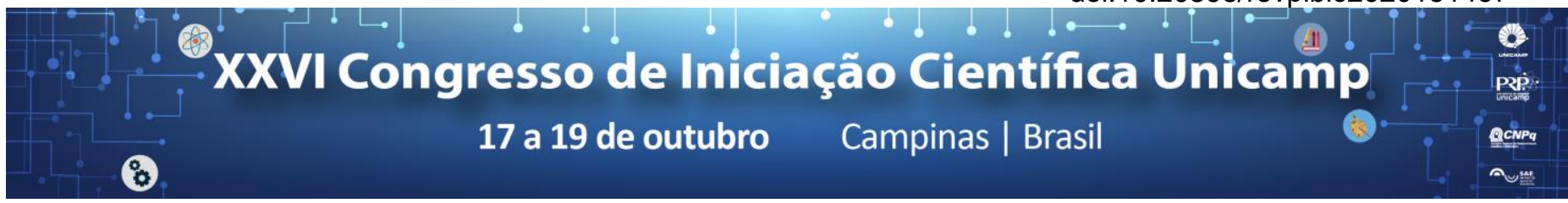

\title{
PESQUISA SOBRE O USO DE INTERFACE NEURAL INTERATIVA EM SISTEMAS AUTÔNOMOS E OUTROS
}

\author{
Bruna L. A. Real, Fernanda N. Silveira, Vitoria C. A. Fernandes, Paulo V. O. Miguel.
}

\begin{abstract}
Resumo
Esta pesquisa situa-se na área de neuroengenharia, com destaque para usabilidade, acessibilidade, biotecnologia e interfaces interativas. Dentre os objetivos, está o de incluir pessoas com necessidades especiais; reduzir o consumo de energia e o impacto ambiental, adequar as interfaces de interação aos sistemas autônomos, aos aparelhos "Wearables" e implantados, à Realidade Virtual, "Internet das Coisas" e ao "Big Data". Pretende-se reduzir as interações biomecânicas, protegendo os membros contra os esforços repetitivos e a contaminação por bactérias. Também reduzir o consumo de energia e autossuficientes, já que poderão captar a energia necessária de outras fontes no próprio ambiente. Simplificando sua concepção, pretende-se reduzir o uso dos recursos naturais, o tempo de fabricação, o custo total e o impacto ambiental.
\end{abstract}

\section{Palavras-chave:}

Neurociências, Interface, Neural, Sistemas Autônomos.

\section{Introdução}

Diariamente, utilizam-se interruptores, interfaces e controles remotos para acionar e controlar todo tipo de aparelho. Melhorar este tipo de interação pode incluir pessoas com necessidades especiais, reduzir o custo de produção, o consumo de energia, de recursos naturais e o impacto ambiental, além de minimizar a contaminação de seus usuários por bactérias que residem nestas interfaces de comunicação e controle.

\section{Resultados e Discussão}

A pesquisa envolveu 4 atividades principais, a saber: Estudos sobre sistemas neurais biológicos, curso sobre inteligência artificial, estudos sobre implementação de Chatbots, sobre as características da língua humana e introdução à linguística pela Universidade de Leiden.

O primeiro semestre do projeto possibilitou a aquisição de informações que mostraram como pequenas coisas do dia a dia de um indivíduo são interpretadas e processadas pelo cérebro e o que parece ser algo simples, tem um mecanismo de funcionamento que para a obtenção do resultado final passa por diversas etapas com detalhes tão pequenos, mas que fazem toda a diferença.

O segundo semestre foi utilizado para explorar e entender algumas pesquisas sobre o desenvolvimento da linguagem humana e algumas tecnologias que poderíamos utilizar para promover a comunicação entre o ser humano e os sistemas autônomos. Dentre as pesquisas sobre 0 desenvolvimento da linguagem com o curso "Milagres da Língua Humana: Uma Introdução à Linguística" (curso disponível no Coursera), e dentre outras tecnologias trabalhamos com o curso "Introdução à Inteligência Artificial" (curso disponível na Udacity) e a plataforma "Watson" da IBM para implementar e testar um chatbot.

\section{Conclusões}

Foram adquiridos novos conhecimentos, tanto na área da fisiologia humana - com foco no cérebro e suas funcionalidades - quanto na área tecnológica, que no futuro poderão possibilitar a criação da interação entre o homem e a máquina, de forma que possamos reduzir ou eliminar chances de riscos para a saúde do indivíduo e para funcionamento do equipamento.
Os aspectos mais relevantes, no entanto, foi o aprendizado sobre o funcionamento do cérebro e dos neurônios. Também sobre como como quais doenças o afetam e afins; além de aprendermos com o curso sobre Linguística pela Universidade de Leiden. As leituras e atividades servirão como base para a continuidade dos trabalhos em busca do desenvolvimento de interfaces específicas para os objetivos do projeto.

\section{Agradecimentos}

Ao Prof. Paulo Victor Oliveira Miguel, do Departamento de Coordenadoria de Relações Escola-Empresa e Estágio do COTUCA, incentivador e mentor, pela orientação e oportunidade de aprendizado. Ao Programa Institucional de Bolsas de Iniciação Científica (CNPq), pela concessão da bolsa. À Pró-reitoria de Pesquisa da Unicamp e à APM - COTUCA (Associação de Pais e Mestres), pelo financiamento.

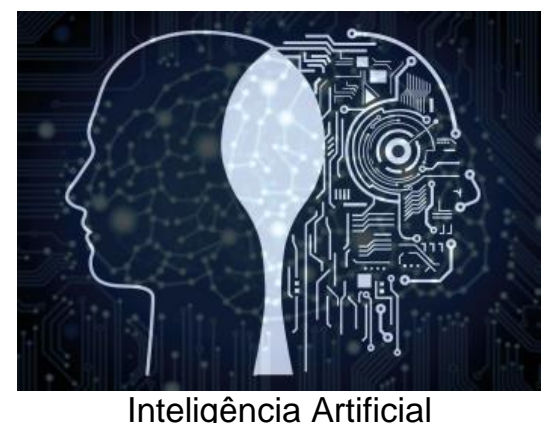

\section{Referências}

OOSTENDORP, Marc van. "Milagres da Língua Humana: Uma Introduçâo à Linguística”. 2016.< https://www.coursera.org/learn/human-language>Acesso em: 21/04/2018.

PORTILO, Rodrigo. "IBM Watson - Como Criar um Chatbot (com PHP e jQuery)".2017.<Https://velhobit.com.br/desenvolvimento/ibm-watson-comocriar-um-chatbot-com-php-e-jquery.html>.Acesso em: 20/06/2018.

UDACITY. "Intro to Artificial Intelligence", 2011. $<$ https://classroom.udacity.com/courses/cs271/lessons/48678875/concepts/486 847720923>.Acesso em: 21/04/2018.

MORRIS, R.; FILLENZ, M. Neuroscience: The Science of the Brain. Liverpool, UK: The British Neuroscience Association, 2003. 